\title{
An Overall Study of Energy Consumption and Savings at Steelworks*
}

\author{
By Tadashi KATADA**
}

\section{Synopsis}

Energy savings at integrated steelworks have been studied from a standpoint that the whole steelworks is regarded as one energy system where the energy is consumed, converted, recovered and transferred.

An analysis of this system indicates that the hot metal ratio of $B O F$ burden, the fuel rate in blast furnace and the production load are considered the three key parameters affecting total energy consumption. Effects of these parameters on overall specific energ y consumption in terms of $k c a l \mid t$-steel have been discussed in some detail.

On the basis of these discussions, eleven technical measures including waste heat recovery, and either elimination or combination of processes have been suggested as promising approaches to the energy savings at integrated steelworks.

In addition, the recent state of energy consumption in Japanese steel industry, particularly at its integrated steelworks, has been investigated using the latest statistics.

\section{Introduction}

The selection of more suitable energy sources, their securement on a more stable basis and utilization at higher efficiencies constitute the critical problems for the steel industry. Over the past two decades, a great deal of $\mathrm{R} \& \mathrm{D}$ efforts have been directed at these fundamental issues. It may be safely said in this sense that changes in the energy utilization techniques have played an important role in the overall history of technical advances in the steel industry.

This can be understood more clearly by looking back over the last two decades of the progress of the Japanese steel industry. Crude steel production grew at $10 \%$ or more annually from the 1960's to the early part of the 1970's thanks in no small measure to the successful solution to many energy problems. Major problems the steel industry faced in relation to energy during that period included, firstly, how to secure a stabilized supply of energy, secondly, the necessity for a shift in fuel sources from coal to oil and, thirdly, how to cope with increasing requirement for cleaner energy from the viewpoint of environmental protection.

The oil crisis which occurred in the latter part of 1973, however, has brought about a drastic change in the way in which industrial users of energy and natural resources recognize and evaluate the importance of resources, and greater research and development emphasis has been laid on energy conservation.

In fact, many steelmakers are very active in seeking new iron- and steelmaking technologies more suitable to this new era of steady energy price rises. Some of these R \& D works are already in the stages of com- mercial application with satisfactory results. It is not easy, therefore, to give some new suggestions or ideas about energy conservation.

What should be noted here, however, is the fact that an integrated steelworks itself constitutes a largescale energy recycling system where energy is consumed, converted, recovered and transferred in an extremely complicated fashion between processes. Because of this, the numerical value of energy savings attained in each process cannot always represent a net total of energy conservation attained throughout the works. In many cases, a correct picture of energy conservation can be obtained only by viewing things from an all-inclusive stance.

Further, steelmaking processes form a continuous flow wherein output products of one process are used as feedstock for the subsequent process. In such a production system, appraisal of energy conservation for each process must be made in relation to preceding or subsequent processes. Common tendencies have been, however, that independent studies for individual processes or plants take precedence in overall studies.

In this paper, a whole steelworks is regarded as one energy system and from such a standpoint various aspects relating to energy conservation are viewed. Also, major courses that future advances in energy conservation technology will take are forecast.

\section{Energy Consumption at Steelworks}

\section{Energy Requirement by Japanese Steel Industry}

As shown in Fig. 1, the steel industry accounts for almost $17 \%$ of the total energy consumption in Japan. In terms of the energy source for the steel industry in the nation's total energy consumption, the industry accounts for $4.9 \%$ of oil, $87.0 \%$ of coal and $15.6 \%$ of electricity.

\section{Energy Requirement at Steelworks}

\section{Scope of Energy and Primary Energy Equivalent}

There can be much argument about the scope of energy to be discussed in relation to energy conservation at steelworks. If a works' requirement for coke, electricity and oxygen is internally satisfied, the real consumption of energy by the works will not be equal to the net amount of energy consumed by the same works when these energy requirements are satisfied externally. Additionally, tar as a by-product of the coke-making process can be regarded as energy if it

* Originally published in Tetsu-to-Hagané, 64 (1978), No. 13, Special Issue on Energy Conservation in Steel Industry, 1827, in Japanese. English version received April 17, 1979.

** Plant Engineering and Technology Bureau, Nippon Steel Corporation, Otemachi, Chiyoda-ku, Tokyo 100. 


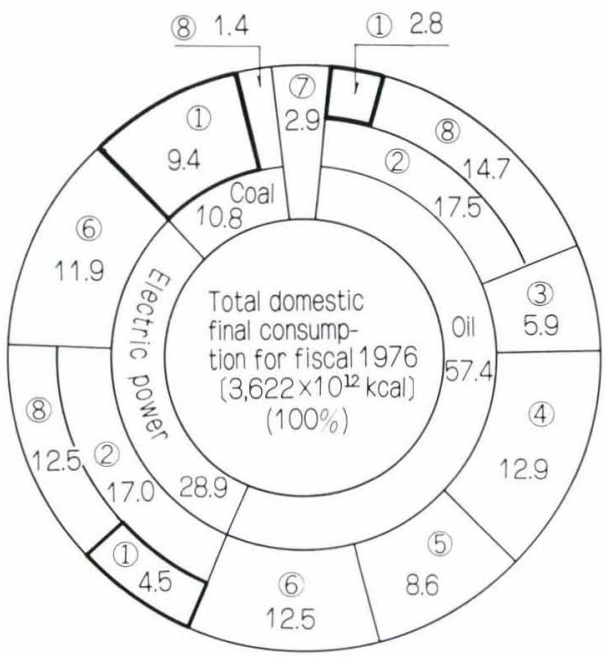

(1) Steel industry

(2) Mining and manufacturing industries

(3) Power generation industry

(4) Transportation industry

(5) Non-energy uses

6) Non-industrial uses

(7) Other type of energy

(8) Others

Fig. 1. Percent distribution of final energy consumption by type of energy and relative importance of the stee industry for fiscal 1976.1)

Table 1. Primary energy equivalents of fuel and utilities. ${ }^{2)}$

\begin{tabular}{|c|c|c|}
\hline Type & $\begin{array}{c}\text { Primary energy } \\
\text { equivalent }\end{array}$ & Remarks \\
\hline Coal & $\begin{array}{l}6500 \sim \\
7750 \mathrm{kcal} / \mathrm{kg}\end{array}$ & $\begin{array}{l}\text { Combustion calorific value } \\
\text { (low) }\end{array}$ \\
\hline Coke & $\begin{array}{l}6800 \sim \\
7200\end{array}$ & $”$ \\
\hline LPG & $\begin{array}{l}10500 \sim \\
12000\end{array}$ & $"$ \\
\hline LNG & $12000 \quad ”$ & " \\
\hline Tar & $\begin{array}{l}8700 \sim \\
8900\end{array}$ & $”$ \\
\hline Heavy oil & $\begin{array}{l}8600 \sim \\
9375 \mathrm{kcal} / l\end{array}$ & $"$ \\
\hline Light oil & $\begin{array}{l}7920 \sim \\
9200\end{array}$ & $"$ \\
\hline Kerosene & $\begin{array}{l}8050 \sim \\
8900\end{array}$ & $"$ \\
\hline $\mathrm{COG}$ & $\begin{array}{l}4400 \sim \\
4800 \mathrm{kcal} / \mathrm{Nm}^{3}\end{array}$ & (mainly at $\dddot{4} 800 \mathrm{kcal} / \mathrm{Nm}^{3}$ ) \\
\hline $\mathrm{BFG}$ & $\begin{array}{l}800 \sim \\
828 \quad,\end{array}$ & 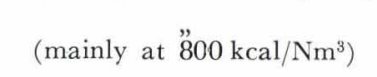 \\
\hline BOF gas & $\begin{array}{l}1800 \sim \\
2500\end{array}$ & (mainly at $2000 \mathrm{kcal} / \mathrm{Nm}^{3}$ ) \\
\hline Steam & $\begin{array}{l}780 \sim \\
980 \mathrm{kcal} / \mathrm{kg}\end{array}$ & Enthalpy \\
\hline Electricity & $2450 \mathrm{kcal} / \mathrm{kWh}$ & Efficiency : $35.1 \%$ \\
\hline Oxygen & $1700 \mathrm{kcal} / \mathrm{Nm}^{3}$ & $\begin{array}{l}\text { Power consumption : } \\
0.694 \mathrm{kWh} / \mathrm{Nm}^{3}\end{array}$ \\
\hline
\end{tabular}

is used as fuel, but it can also be regarded as either energy or a finished product if it is sold. Ferroalloys, brick, rolls and moulds may be regarded as materials having consumed a large quantity of energy in their production. Also, scrap may be considered energy-

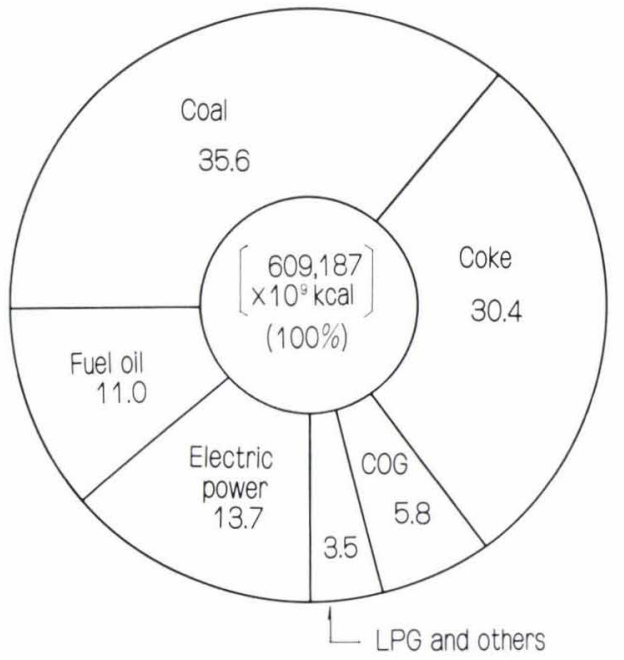

Fig. 2. Percent distribution of purchased energy for Japanese integrated steelworks for fiscal 1976. ${ }^{2}$

bearing materials unlike iron ores, the starting materials.

Practically, however, ferroalloys and scrap are not regarded as energy while electricity and oxygen, purchased or internally produced, are treated as energy and translated into primary energy. Conversion of these types of energy into primary energy equivalents is advantageous in that effects of any changes in energy prices on the costs of finished steel products can be readily calculated.

Meanwhile, the energy statistics compiled and published by the Heat Economy Technology Committee of ISIJ covers every type of energy used in its member establishments (including all Japanese integrated steelworks) and reveals the primary energy equivalent of each type as shown in Table 1.

\section{Purchased Primary Energy}

Percent distribution by type of the quantity of purchased primary energy for 21 integrated steelworks for fiscal 1976 is shown in Fig. 2. This statistical data is compiled on the basis of the assumptions given in Table 1 .

As seen in the figure, an average Japanese integrated steelworks relies on coal-based energy for about $70 \%$, on oil-based energy for $15 \%$ and on electricity for $15 \%$ of its total requirement for purchased energy.

\section{Overall Energy Consumption at Steelworks}

The overall energy consumption per ton of steel produced is indicated usually as a relation expressed in $\mathrm{kcal} / \mathrm{t}$-steel between the total quantity of primary energy consumed for a given period by the steelworks as a whole and the aggregate tonnage of crude steel produced by the steelworks for the same period. Commonly, the overall energy consumption is put at approximately $6000 \times 10^{3} \mathrm{kcal} / \mathrm{t}$-steel.

As obvious from the definition of the term, the energy consumption per ton of steel is based on the assumption that the product-mix, equipment type, production size, hot metal ratio and other factors affecting to a great extent the overall energy consumption at steelworks are as prevailing at present. 
The overall energy consumption per ton of steel cannot therefore be an effective means of comparing the real energy efficiency between steelworks, but it does offer a convenient macro-indicator in dealing with energy problems of steelworks. To avoid confusion, the energy consumption in terms of $\mathrm{kcal} / \mathrm{t}$-steel is hereinafter called "the overall energy consumption per ton of steel". This indicator should be dealt with for a long period of at least a quarter, or desirably a year because it might otherwise entail various extraordinary factors such as those derived from shutdown for regular maintenance or accidents and from short-term changes in the product- and size-mix and, as a result, become meaningless as a macro-indicator.

A chronological change in the average overall energy consumption per ton of steel for Japanese integrated steelworks is given in Fig. 3. The figure shows net energy consumption, or the quantity of

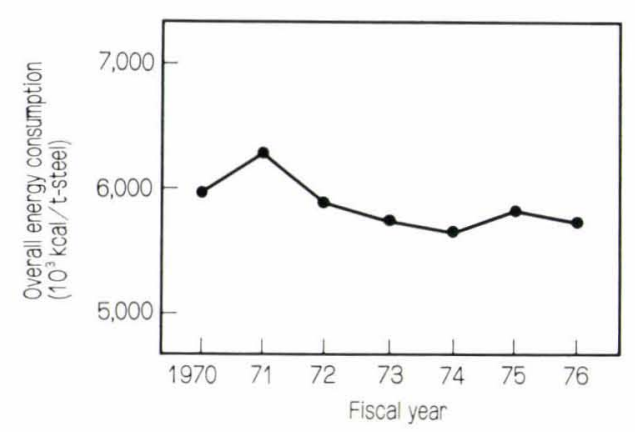

Fig. 3. Change in average overall energy consumption per ton of steel for Japanese integrated steelworks (in terms of net consumption). ${ }^{2}$ purchased energy less the quantity of energy sold outside.

As is evident, there was a steady improvement in the overall energy consumption between fiscal 1971 and 1974. The slight increase in energy consumption from 1975 to 1976 was due to increased requirements for energy for antipollution purposes and to production curtailment since the oil crisis.

\section{Energy Flow at Steelworks}

A typical flow of various types of energy in steelworks is illustrated in Fig. 4. This flow chart is made on the basis of the real consumption of energy at Nippon Steel Corp. (NSC), Nagoya Works, for the 3rd quarter of fiscal 1977.

It should be noted, however, that such an energy flow chart inevitably entails to a certain degree lack of accuracy because of:

1) A time lag between supply and real consumption of fuel;

2) Difference between actual calorific value and standard calorific value set for statistical purposes;

3) Variance of real energy consumption from apparent consumption that will develop when converting purchased electricity and oxygen into primary energy equivalents; and

4) Errors associated with setting of conditions because of impracticability of simultaneous measurement of heat energy balance for the entire steelworks.

As with the overall energy consumption per ton of steel, the energy balance should also be considered

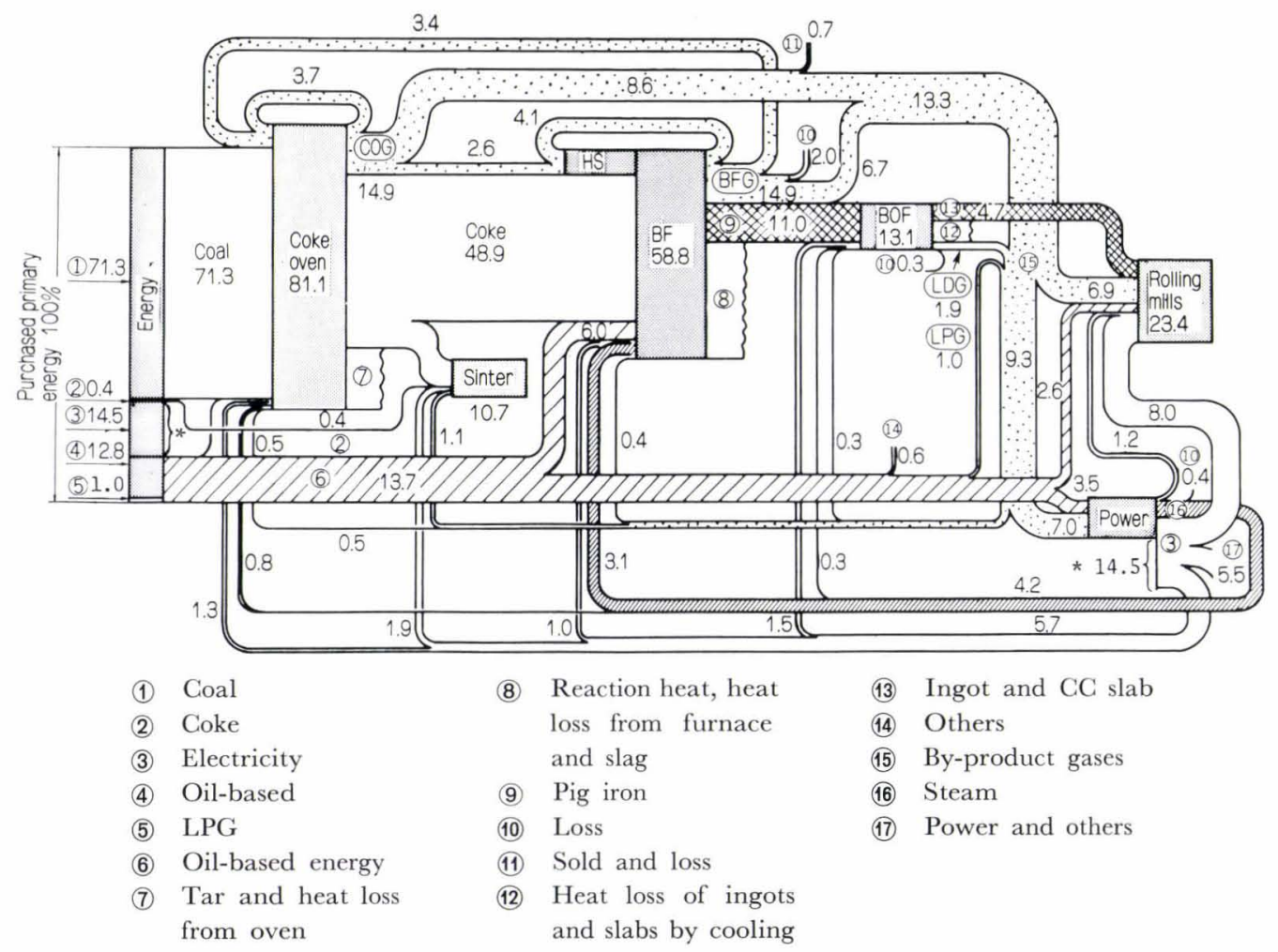

Fig. 4. Energy flow chart for medium-size steelworks (Nippon Steel Corp., Nagoya Works, for 3rd quarter of fiscal 1977). 
from a long perspective suitable to each application in order to assure its long-term control. From the viewpoint of energy distribution control, on the other hand, continuously updated data on energy balance is required.

Hence, to study a structure of steelmaking energy consumption, it seems necessary to employ selectively for particular uses two models: a static model that deals with an average quantity for a given period and a dynamic one that deals with ever changing quantities.

Figure 4 is a static flow chart. As seen in the figure, the bulk of the energy flow in steelworks is controlled by the ironmaking sector, that is, coke ovens, blast furnaces and sintering plants. In quantitative terms, as much as $80 \%$ of the total purchased energy is directed to this sector. The ironmaking sector is important also as a major source of coke oven gas (COG) and blast furnace gas (BFG), which are fed as gaseous fuel to various plants in the steelworks. When allowing for this energy transfer, the ironmaking process accounts for approximately $65 \%$ of the quantity of energy consumed in the steelworks as a whole. More accurately, the carbon content of pig iron should be deducted from coke consumption in blast furnaces. Usually, however, this is not done. Since BOF gas (LDG) is produced from this carbon in the steelmaking process, theoretically there can be cases where the energy consumption of the BOF plant as a whole shows a negative value.

\section{Energy Consumption for Individual Processes and Prod- ucts}

Table 2 shows energy consumption by process for Nagoya Works. As foot-noted, each consumption figure is per ton of starting materials used in the process involved (power plants: per ton of acceptable steel ingot).

The remarkably low values of energy consumption in the steelmaking process compared with the others are for statistical reasons associated with statistical treatment of heat generated by the oxidation of carbon, silicon and manganese contained in pig iron. (These components, which consume heat during the reduction process in blast furnaces and release oxidation heat in the steelmaking process, are not usually reckoned as a heat input in LD converters.)

Table 3 presents a typical calculation of the accumulated energy requirement per ton of product for each process, or the accumulative total energy inputs required to produce one ton of product from the ironmaking process up, for a model process flow from steelmaking to sheet coating. Such an energy consumption per ton of product is necessarily influenced by a process parameter-yield.

\section{Final Form of Energy Consumption}

Figure 5 shows an example of the final forms of energy consumed in steelworks. The figure deals with the energy consumption throughout Nippon Steel Corp. works during the first half of fiscal 1975. Statistics of this type often entail problems in the definition of each item of consumption, different objectives of tabulation or philosophy in the compilation of statistics resulting in different classification or statistical figures, but it does offer a basis on which energy conservation measures should be studied.

\section{Parameters Influencing Overall Energy Consumption per Ton of Steel}

In the foregoing chapter an actual picture of the structure of energy consumption at integrated steelworks is overviewed by citing the statistics published by the Heat Economy Technology Committee of ISIJ and data on actual energy consumption for a mediumsize steelworks. In this chapter the energy consumption structure and its characteristics are discussed on the basis of a new approach wherein a whole steelworks is regarded as one energy system and the effects of any changes in the parameters of the system on the total system are investigated.

\section{Key Parameters Influencing Overall Energy Consumption}

The real status of energy consumption of a steelworks can be indicated typically by the total energy consumption and the overall energy consumption per ton of steel. For the purpose of this study, however, the latter is used as a representative indicator of energy consumption of a steelworks.

With characteristics as already discussed in Section II. 3, however, this indicator is not always effective in quantitative analyses.

Now, suppose the overall energy consumption of a steelworks comprises an average energy consumption and deviations from the average. The former is determined basically by the product-mix and equipment-type, production scale, etc., of the steelworks. In other words, this portion of the overall energy consumption is a heteronomous prerequisite to individual steelworks.

The latter portion, on the other hand, represents an autonomous one which can be controlled by the steelworks itself through, for instance, concentration of production lots, process design and operational and equipment improvements. (Though division of production and products between a number of steelworks, if efficiently worked out on a company-wide basis, will prove an effective energy conservation measure, such practices as encompassing many steelworks are not discussed here.)

In conclusion, the overall energy consumption per ton of steel is considered to be influenced mainly by the following three parameters (see Fig. 6):

1) The hot metal ratio of BOF burden;

2) The fuel rate in $\mathrm{BF}$; and

3) Production load.

Each of these parameters has both the characteristic of the average portion and that of deviations aforementioned; which to use as a measure depends on whether these parameters are viewed from a shortterm perspective or from a long or medium-term perspective. The relation between each of the parameters and the overall energy consumption is hereunder discussed. 
Table 2. An example of energy consumption by process $\left(10^{3} \mathrm{kcal} / \mathrm{t}\right.$-product). (Nagoya Works, Nippon

\begin{tabular}{|c|c|c|c|c|c|c|c|c|c|}
\hline \multirow{5}{*}{ Type of energy } & \multicolumn{9}{|c|}{ Plant } \\
\hline & \multicolumn{2}{|c|}{$\begin{array}{l}\text { Coke (inclusive } \\
\text { of COG refining) }\end{array}$} & Sinter & \multicolumn{2}{|c|}{$\mathrm{BF}$} & \multicolumn{2}{|c|}{ BOF (CC) } & Slabbing & Hot strip \\
\hline & & & & & & \multicolumn{4}{|c|}{ Throughput $\left(10^{3} \mathrm{t} / \mathrm{M}\right)$} \\
\hline & \multicolumn{2}{|c|}{171} & 471 & \multicolumn{2}{|c|}{338} & \multicolumn{2}{|c|}{361} & 186 & \multirow{2}{*}{$\frac{266}{\underbrace{\text { tion }}_{\text {Consump }}}$} \\
\hline & $\begin{array}{l}\text { Consump- } \\
\text { tion }\end{array}$ & Production & $\begin{array}{l}\text { Consump- } \\
\text { tion }\end{array}$ & $\begin{array}{l}\text { Consump- } \\
\text { tion }\end{array}$ & Production & $\begin{array}{c}\text { Consump- } \\
\text { tion }\end{array}$ & $\begin{array}{l}\text { Produc- } \\
\text { tion }\end{array}$ & $\begin{array}{c}\text { Consump- } \\
\text { tion }\end{array}$ & \\
\hline Coal & 10023 & & & & \multirow{8}{*}{$\begin{array}{lr}\triangle & 29 \\
\triangle & 1074\end{array}$} & \multirow{5}{*}{93} & \multirow{8}{*}{$\begin{array}{l}\triangle 11 \\
\triangle 147\end{array}$} & & \\
\hline Coke & & $\triangle 7200$ & 375 & 2992 & & & & & \\
\hline Fuel oil & 19 & & & 433 & & & & & 233 \\
\hline Electricity & 152 & & 90 & 68 & & & & 83 & 223 \\
\hline $\mathrm{BFG}$ & 488 & & 1 & 296 & & & & 34 & 10 \\
\hline $\mathrm{COG}$ & 529 & $\triangle 2120$ & 47 & 190 & & 22 & & 113 & 100 \\
\hline Steam & 107 & $\triangle \quad 32$ & 3 & 222 & & 22 & & 3 & 22 \\
\hline Others & 34 & $\triangle \quad 595$ & 4 & 58 & & 110 & & 63 & 38 \\
\hline Sub-total & 11352 & $\triangle 9947$ & 520 & 4259 & $\triangle 1103$ & 249 & $\triangle 158$ & 296 & 626 \\
\hline Grand total & \multicolumn{2}{|c|}{1405} & 520 & \multicolumn{2}{|c|}{3156} & \multicolumn{2}{|c|}{91} & 296 & 626 \\
\hline
\end{tabular}

Notes: 1) For coke-making to steelmaking processes, energy consumption figures are per ton of each product.

2) For the rolling process, energy consumption figures are per ton of slabs charged.

3) For power plants, energy consumption figures are per ton of crude steel.

Table 3. Accumulative energy consumption for strip (Typical calculation).

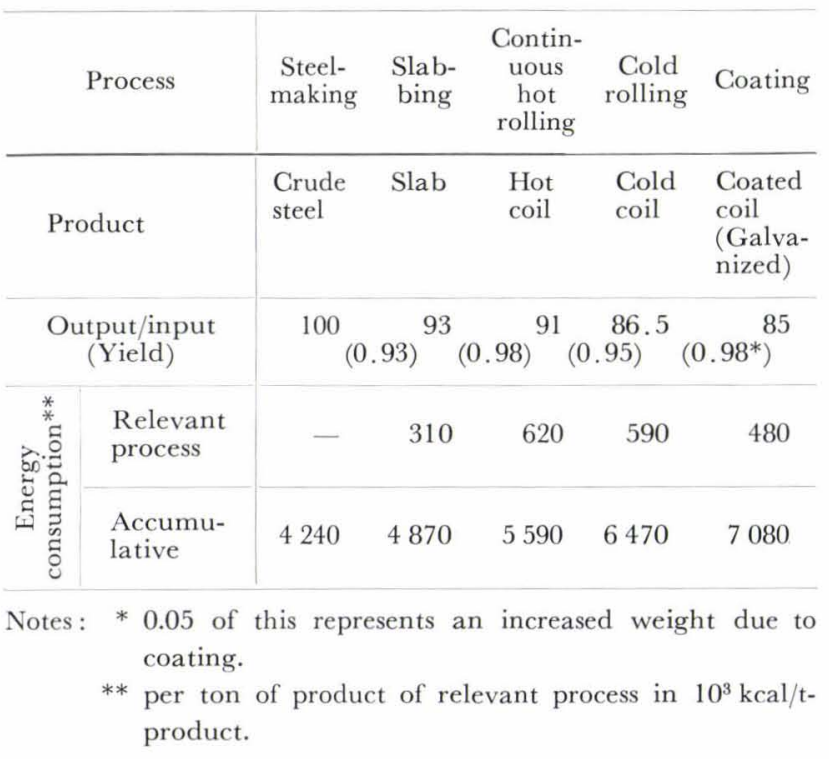

\section{Hot Metal Ratio vs. Overall Energy Consumption}

As already discussed in Subsection II. 2. 1, scrap is not usually reckoned as energy. Because of this, the quantity of hot metal consumed to produce a given tonnage of crude steel, or hot metal ratio (HMR), constitutes a decisive influence on the overall energy consumption of a steelworks. The relation between HMR and accumulative energy requirement per ton of liquid steel, or the total amount of energy required to produce a ton of molten steel, is indicated in Fig. 7. Generally, a $\pm 1 \%$ fluctuation in the hot metal ratio will have an effect of as large as \pm 40 to $50 \times 10^{3} \mathrm{kcal} /$ $t$-steel on the overall energy consumption.

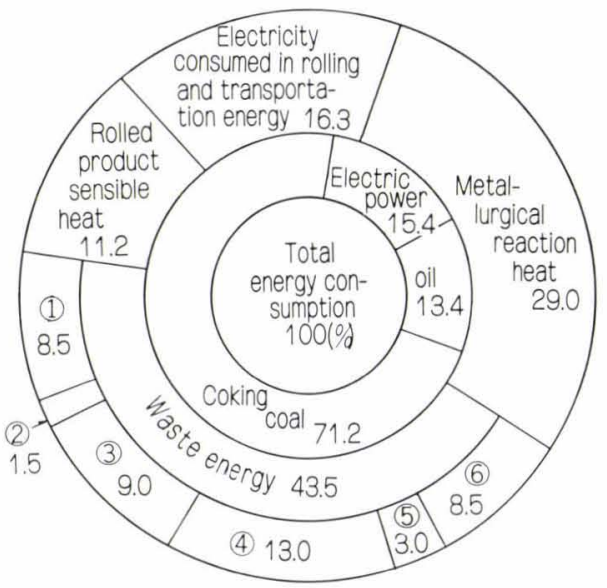
(1) Heat loss from furnaces
(2) Others
(3) Heat loss to cooling water
(4) Sensible heat of products
(5) Sensible heat of gases
(6) Combustion waste gas

Fig. 5. An example of final forms of energy consumption (actual results at Nippon Steel Corp., for 1st half of fiscal 1975). ${ }^{3)}$

In practical operation the hot metal ratio is usually set at 80 to $90 \%$ allowing for return scrap. During a period of increased production, the overall energy consumption tends to decline since purchased scrap is used to make up for the shortage of hot metal.

\section{BF Fuel Rate vs. Overall Energy Consumption}

As previously stated, the iron-making sector accounts for about $65 \%$ of the total energy consumption of a steelworks. Blast furnaces alone account for $50 \%$ of the total energy consumption. The characteristics 
Steel Corp.; for 3rd quarter of 1976)

\begin{tabular}{|c|c|c|c|}
\hline Plate & $\begin{array}{l}\text { Cold strip, } \\
\text { Pipe }\end{array}$ & \multicolumn{2}{|c|}{ Power } \\
\hline 54 & 271 & \multicolumn{2}{|c|}{$(361)$} \\
\hline Consumption & Consumption & Consumption & Production \\
\hline & & 229 & \multirow{4}{*}{$\triangle 285$} \\
\hline 234 & 352 & 317 & \\
\hline 1 & 1 & 421 & \\
\hline 245 & 197 & 38 & \\
\hline 23 & 112 & 492 & \multirow[t]{2}{*}{$\triangle 602$} \\
\hline 349 & 46 & 97 & \\
\hline 852 & 708 & 1594 & $\triangle 887$ \\
\hline 852 & 708 & \multicolumn{2}{|c|}{707} \\
\hline
\end{tabular}

4) For others LDG, LPG, kerosene and gasoline, oxygen, nitrogen, compressed air, water and tar are included.

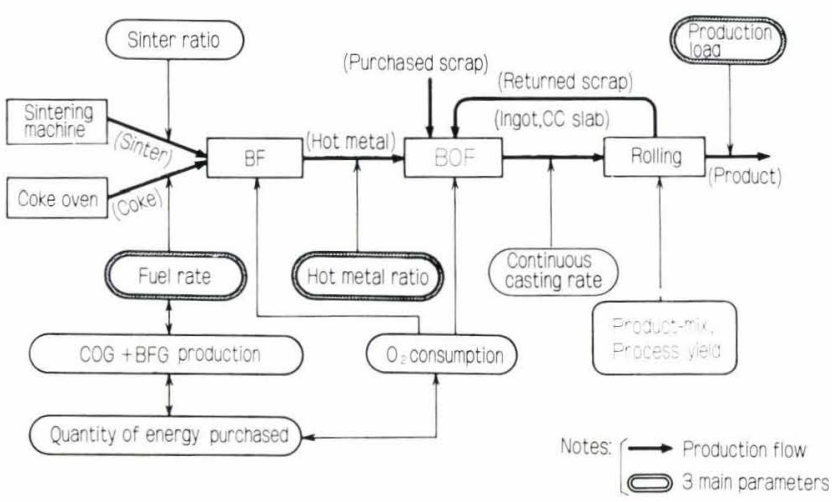

Fig. 6. Three main variable parameters affecting overall energy consumption at steelworks. ${ }^{4)}$

of blast furnaces as a major source of fuel gases make them of particular importance in the entire energy system.

The blast furnace fuel rate (in $\mathrm{kg}$-fuel/t-pig) is the sum of the coke rate (in kg-coke/t-pig) and the oil rate (in kg-oil/t-pig) and is used as a basic indicator of the operational performance of blast furnaces.

A variety of approaches are adopted to improve the blast furnace fuel rate, including improvements in burdens, parallel operation of hot stoves, blast furnace operational practices and blast furnace equipment. The energy conservation benefits expected from these improvements depend on the blast furnace fuel rate and the hot metal ratio in BOFs. As indicated in Fig. 8, which illustrates the effect of the fuel rate on the overall energy consumption, a change of $\pm 10 \mathrm{~kg} /$ t-pig in the fuel rate may produce a change of $\pm 50 \times$ $10^{3} \mathrm{kcal} / \mathrm{t}$-steel in the overall energy consumption.

As will be discussed later, blast furnaces, though very simple in construction, are apparatuses with an

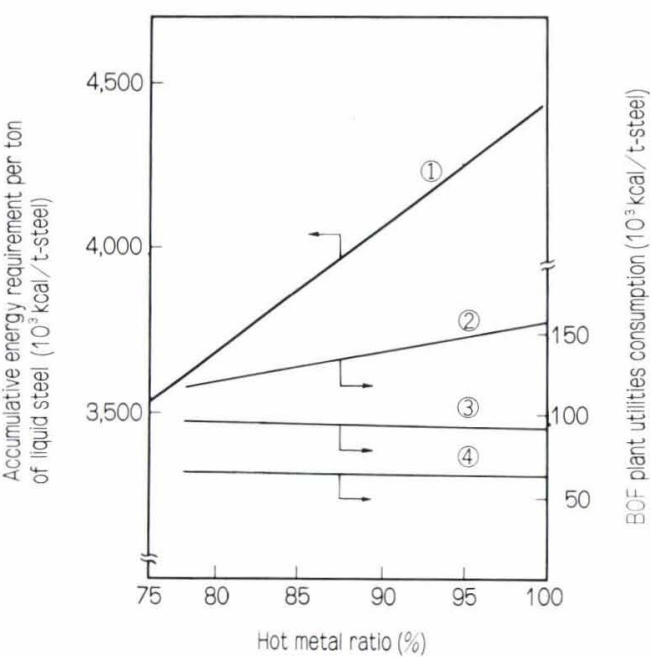

(1) Accumulative energy requirement per ton of liquid steel

(2) LDG production (recovered)

(3) $\mathrm{O}_{2}$ consumption

(4) Electricity consumption

Assumed conditions for calculation

Energy requirement of pig iron: $4280 \times 10^{3} \mathrm{kcal} /$ t-pig

Energy equivalent of scrap: $0 \mathrm{kcal} / \mathrm{t}$-scrap

Fig. 7. Hot metal ratio $v s$. accumulative energy requirement per ton of liquid steel (Nippon Steel Corp., Hirohata No. 2 Steelmaking Plant, for October, 1974).

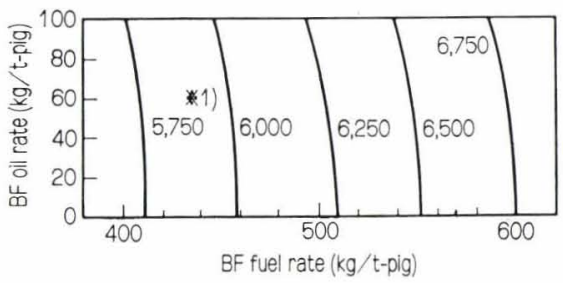

*1) Overall energy consumption $\left(10^{3} \mathrm{kcal} / \mathrm{t}\right.$-steel $)$ Estimated for a medium-size steelworks at constant pig iron and steel productivities and at $80 \%$ hot metal ratio.

Fig. 8. Blast furnace fuel rate vs. overall energy consumption. ${ }^{4)}$

exceptionally high thermal efficiency capable of preheating, reducing and melting iron ores in a highly systematic manner, and the fuel rate is approaching the theoretical limit. To take measures to reduce it substantially below the present level, therefore, may not only cause operational difficulties but may result in increased requirements for energy (additional energy requirements to realize, for example, higher temperature and blast pressure), thereby impairing the overall energy conservation benefits stated above and eventually deteriorating the overall economy itself.

For general information, the relationship between the blast furnace fuel rate and $B F G$ generation in terms of calorific value for a $2500 \mathrm{~m}^{3}$ blast furnace is shown in Fig. 9.

\section{Production Load vs. Overall Energy Consumption}

In discussing any relationship that may exist between the production loads and the overall energy 
consumption, various conditions should be assumed in advance. Generally, however, the following can be said:

(1) Production curtailment $\rightarrow$ hot metal surplus $\rightarrow$ increased hot metal ratio (decrease in the quantity of scrap purchased) $\rightarrow$ increase in overall energy consumption per ton of steel; or

(2) Production curtailment $\rightarrow$ equipment redundancy $\rightarrow$ increased cases where operation must be continued only for keeping productive facilities " hot" or under no or low loads $\rightarrow$ increase in overall energy consumption per ton steel.

In case of production increase, the reverse can be said.

Capacity surplus, on the other hand, will offer increased opportunities to step up energy conservation measures such as increased continuous casting rates and direct rolling rates and optimized operational practices for reheating furnaces. It cannot always be said, therefore, that production curtailment will result in a rise in the overall energy consumption.

Figure 10 shows the relation between production load and the overall energy consumption per ton of steel for a large-size steelworks with an annual crude steel production capacity of 12.0 million tons. In the figure only the relation between the crude steel output and the overall energy requirement per ton

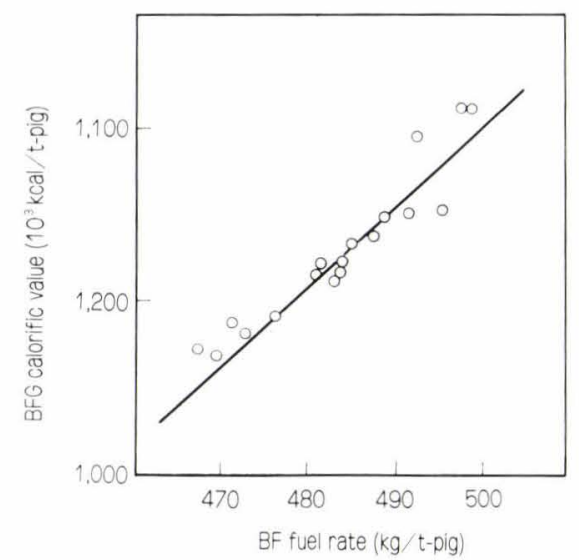

Fig. 9. BF fuel rate $v s$. BFG production in terms of calorific value (Nippon Steel Corp., Hirohata No. 4 BF, from Oct., 1973 to Apr., 1975).

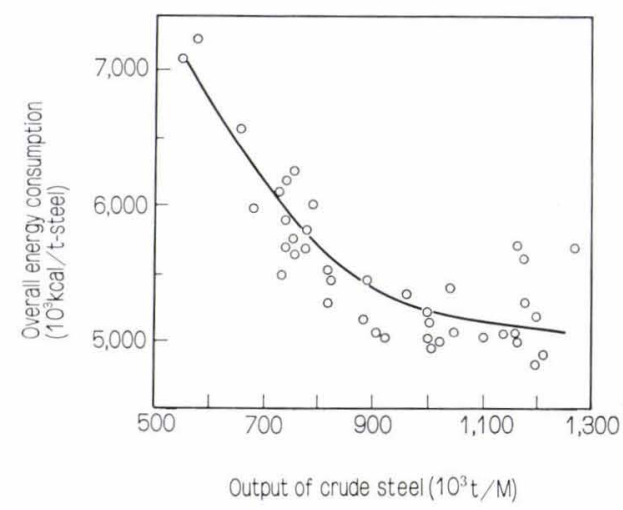

Fig. 10. Production load vs. overall energy consumption (for a large-size steelworks). ${ }^{5}$ of steel is indicated though it is presumable that some measures for production increase including capacity addition may have been taken in the period covered.

\section{Blast Furnace Fuel Rate vs. Energy Balance}

In recent years the energy consumption per ton of steel has been reduced markedly thanks to reduced blast furnace fuel rates. However, this has coincided with decreased production of blast furnace gas and coke oven gas and, as a result, there has been a drastic change in the pattern of the overall energy balance in the steelworks.

Previously, what is termed "integrated steelworks" meant not only a continuously integrated iron and steel works but also energy self-sufficiency requirements. In fact, many integrated steelworks could satisfy all of their demands for fuel and electricity with blast furnace gas and coke oven gas internally produced. Later, however, the improved blast furnace fuel rates gradually reduced the availability of these by-product gases on one hand, and as requirements increase for steel products with greater value added the cold rolling mill and surface treatment plant facilities were expanded, with the result of increased energy requirements in these processes. Earlier, deficiency in the supply of by-product gas was made up for by feeding boilers and reheating furnaces with fuel oil, but with increasingly stringent anti-pollution regulations such a deficiency has in recent years been made up for by low-sulfur oil or cleaner LPG and LNG.

Figure 11 shows the relation between the overall energy consumption per ton of steel and the deficiency in the supply of by-product energy sources estimated for a medium-size steelworks by varying the blast furnace fuel rates at a constant oil rate of $60 \mathrm{~kg} / \mathrm{t}-$ pig. As indicated in the figure, the deficiency for the steelworks under study in the supply of by-product energy sources, or the requirement for purchased energy (including electricity) other than coal and heavy oil for blast furnace injection, amounts to about $18 \%$ of its total energy consumption. If this is to be reduced to zero, the blast furnace fuel rate should

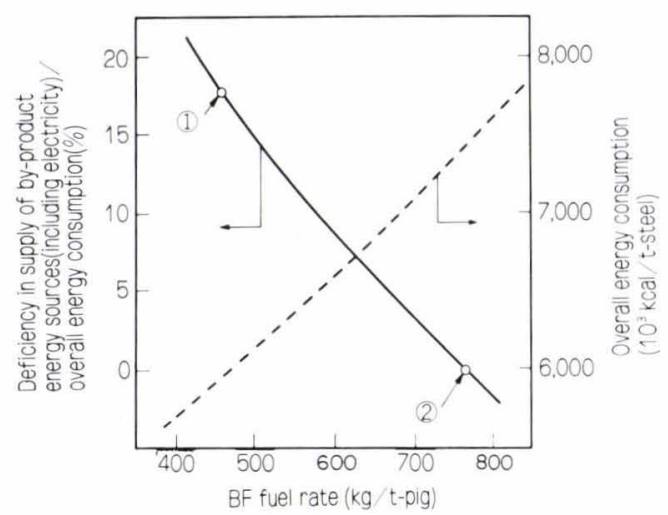

(1) Present level

(2) By-product energy balancing point

Estimated for a medium-size steelworks at an oil rate of $60 \mathrm{~kg} / \mathrm{t}$-pig

Fig. 11. BF fuel rate $v s$. overall energy balance. ${ }^{5)}$ 
be about $750 \mathrm{~kg} / \mathrm{t}$-pig (of which $60 \mathrm{~kg} / \mathrm{t}$-pig is shared by fuel oil) and the overall energy consumption about $7500 \times 10^{3} \mathrm{kcal} / \mathrm{t}$-steel. (In this case it is needless to say that a production balance cannot be attained without addition of blast furnace and coke oven capacities.)

\section{Overall Study of Energy Conservation}

With the characteristics of the structure of steelmaking energy consumption and the overall energy consumption per ton of steel discussed in the foregoing chapters duly considered, an overall study of the future energy conservation is made in this chapter with particular emphasis on the overall technical trend rather than on individual problems and approaches associated with energy conservation.

There are several aspects of the question that must be considered in studying this. The first relates to the production sharing between steelworks for orders received. Such problems as relating to a number of steelworks within a company are beyond the scope of this article, there is no doubt that concentrated production holds the key to efficient energy conservation on a company-wide basis particularly when production curtailment is prevailing.

The second is how to realize improvements in the iron, process and order yields. As can be gathered from the accumulative energy consumption by product illustrated in Section II. 5 and Table 2, no greater loss of energy can be conceivable for the steelworks than the loss of iron itself, degradation of finished products and arising of scrap.

The third pertains to the stabilization of operation and equipment. Since processes from iron-making through rolling are integrated and, in addition, main processes are operated continuously, any instability in operation or failure of equipment at some sector, transient or not, can have a tremendous effect on the entire operation of the steelworks, resulting in great losses including energy.

The fourth is to put greater stress of energy conservation efforts on the iron-making sector which accounts for the largest part of the total energy consumption. As blast furnaces, hot stoves and coke ovens which comprise a major portion of the overall capacity of this sector are operated at already high thermal efficiencies; however, further energy savings in this field will necessarily be limited technically and, therefore, further $\mathrm{R} \& \mathrm{D}$ effort is awaited.

The fifth is an approach from the viewpoint of parameters influencing to a large extent the overall energy consumption, namely, the hot metal ratio, production load and blast furnace fuel rate. Of these, the former two depend almost entirely on a companywide production plan and, therefore, what is left as the target of energy conservation measures to be taken at steelworks is only the blast furnace fuel rate.

The sixth is to improve the conditions under which feed stock is transferred from one process to another in the continuously integrated steelworks. Direct charging of hot slabs into reheating furnaces (socalled hot charge) can be one of these.
The seventh relates to elimination, combination or continuous integration of processes. The former involves the direct rolling system wherein reheating furnaces are by-passed while the latter includes the integration of electrolytic cleaning, continuous annealing and temper rolling into a single line. Such approaches not only provide energy conservation but offer many other benefits such as improved yields, reduced process time and reduced frequency and volume of materials to be transported.

The eighth is to recover waste energy. This approach can be divided into two: one that requires some technical innovation and the other that can be solved purely from the economic standpoint by comparing energy prices with the cost expected to be incurred to recover waste energy.

Naturally, however, greater emphasis of R \& D should be placed on improved efficiency of energy utilization so as to reduce the overall energy inputs rather than on recovery of waste energy.

The ninth is to attain more efficient utilization of by-product gas. To this effect, it is necessary to minimize loss of such energy sources by adequately controlling the distribution of blast furnace and coke oven gas to reheating furnaces, boilers and other combustion facilities.

The tenth relates to rapidly increasing demands for energy by anti-pollution equipment. To cope with this, development of such pollution abatement techniques as will minimize energy requirement will be essential.

The eleventh, which seems more or less different in nature from the foregoing, pertains to further standardization of steel products (in both quality and size). Though hard to determine quantitatively, the energy conservation obtainable from the standardization of industrial goods is thought to be considerable on a nation-wide basis.

The foregoing lists major points to which due consideration should be given in pursuing energy conservation measures. Out of these, some particular approaches to energy conservation are discussed hereunder.

\section{Blast Furnace Fuel Rate vs. Energy Conservation}

Since blast furnace fuel rates have a great effect on the overall energy consumption of steelworks as already discussed in Section III. 3, various measures have been taken to date to reduce the fuel rates. Some of the results of these efforts are evident in Fig. 12. As seen in the figure, the average productivity coefficient and fuel rate for the Japanese steel industry have been improved from year to year with noticeable energy conservation brought about.

However, these operational improvements are nearing a practical limit. If a blast furnace is considered a heat exchanger accompanying chemical reactions, as the fuel rate declines the blast volume or the generated gas volume will decrease accordingly, thereby resulting in instability in the thermal equilibrium in the furnace. In Fig. 12 this is termed " a limit for stable operation". At the current technical level 
the marginal value is estimated at 450 to $460 \mathrm{~kg} / \mathrm{t}$-pig for practical operations and the lower limit around $430 \mathrm{~kg} / \mathrm{t}$-pig.

Blast pressures and temperatures have also been raised substantially in recent years. Here again, however, they are approaching the "economical limits" in terms of capital investment. What should be noted first of all is the fact that to seek higherpressure and higher-temperature blasting necessitates greater energy input. In fact, cases can often be seen that despite energy conservation achieved at least within the framework of the blast furnace system the overall energy balance for the entire steelworks is not improved so much.

These considerations suggest that greater emphasis of research and development to be carried out in the future in this specific field should be laid on how far the fuel rate can be reduced in blast furnace operation with lower productivity coefficients. Along with this, greater importance will be attached to a stabilized operation of blast furnaces since such operational abnormalities as emergency blowing-down and hang-

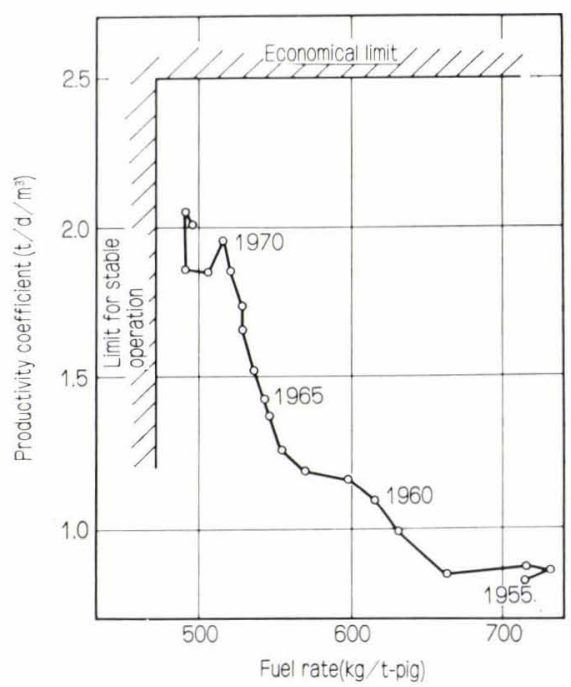

Fig. 12. Changes in blast furnace fuel rate and productivity coefficient (national average) (Source: Nippon Steel Corp.). ing mean a tremendous loss of energy not only in blast furnaces but in the entire steelworks.

\section{Material Transfer between Processes vs. Energy Con- servation}

The temperature, quality, size, shape and other conditions of materials transferred from one process to another in an integrated production line should also be reviewed from the standpoint of energy conservation.

\section{Maintenance of Temperatures}

Figure 13 illustrates the temperature change of stock from one process to another. This figure seems to give important suggestions as to energy conservation measures to be taken by individual steelworks, including:

(1) Prevention of heat loss incidental to the drop in the temperatures of stock between processes; and

(2) Utilization of sensible heat of the preceding process through combination of adjacent processes.

A more precise discussion of these is made hereunder.

(1) Sensible Heat of Hot Metal and Liquid Steel

The temperature drop of hot metal occurring between $\mathrm{BF}$ and $\mathrm{BOF}$ is put at $50^{\circ}$ to $130^{\circ} \mathrm{C}$, while the temperature drop of molten steel from tapping to teeming into ingot molds is about $50^{\circ}$ to $80^{\circ} \mathrm{C}$. Either means a heat loss of $2000 \mathrm{kcal} / \mathrm{t}$-hot metal per $10^{\circ} \mathrm{C}$.

If this temperature drop can be effectively prevented, iron ores to be charged into BOFs can be increased by amounts equivalent to the calorific value that might otherwise be lost. When this is considered, coupled with the resulting increase in the availability of metallics, the effective prevention of temperature drop of hot metal and molten steel is translated into energy conservation several times as large as the loss of sensible heat. Among concrete measures conceivable to this end are installation of ladle covers, prevention of heat loss of molten steel poured from ladles, speedier transportation and so on.

(2) Utilization of Sensible Heat and Solidification Heat of Steel Ingot

The sensible heat and latent heat during solidification of steel ingots represent a heat input to the sub-

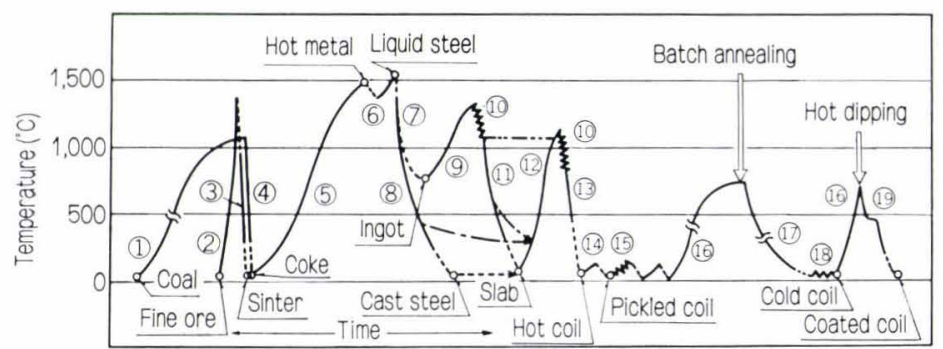

Legend:

$\sim$ Heating

Forced cooling

-.-. Natural cooling

mw Rolling

-..- Direct rolling

-.- Hot charge

(1) Coke oven
(2) Sintering machine
(3) Cooler
(4) Quenching tower
(5) $\mathrm{BF}$
(6) $\mathrm{BOF}$
(7) Ingot making

(8) CC machine
(9) Soaking pit
(10) Hot rolling
(11) Cooling yard
(12) Reheating furnace
(13) Runout table
(14) Pickling

(15) Cold rolling

(16) Annealing furnace

(17) Cooling cover

(18) Skinpass rolling

(19) Plating bath

Fig. 13. An example of temperature change in fully integrated production line (for strip). 
sequent process, soaking pits. Energy conservation can therefore be attained by reducing the track time (time required for a cycle from the end of pouring to ingot charging into soaking pits). For sensible heat alone, the expected energy conservation is as much as approximately $1500 \mathrm{kcal} / \mathrm{t}$-ingot for every prevented temperature drop of $10^{\circ} \mathrm{C}$. The actual energy conservation will vary with the grade of steel because of varying thermal efficiencies of soaking pits, but the overall energy conservation is of the order of several times the above figure.

In recent years the track time control and the acceptability control for soaking quality have been intensified by the use of computers. Additionally, for the better use of latent heat of solidification, steel is charged into soaking pits as partially solidified or directed as partially solidified to slabbing or blooming mills in some steelworks. In pursuing these ways, however, further study must be made on the possible effects on steel qualities such as surface properties and on operational safety of rolling of partially solidified steel ingots.

(3) Utilization of Sensible Heat of Slabs

Typical of this approach is the so-called hot charge, wherein hot slabs fed from slabbing mills or continuous casters are charged into reheating furnaces. As many studies have been reported on this method, reference in detail to this is not made here, but it should be stressed that for the successful employment of this practice measures to eliminate or reduce defects of slabs, to automate detection and conditioning of defects and to match the tapping schedule with rolling schedule must be established. It must also be taken into account that hot slab charging will automatically raise the temperature of waste gas from reheating furnaces.

\section{Energy Conservation through Elimination or Combination of Processes}

Typical embodiments of this approach can be seen in continuous casting and direct rolling. Such elimination or combination of processes require in many cases development or introduction of new processes or equipment.

\section{Continuous Casting}

As is well known, the continuous casting process eliminates ingot heating in soaking pits and primary rolling. The energy saving obtained mainly from the elimination of the soaking process amounts to 150 to $200 \times 10^{3} \mathrm{kcal} / \mathrm{t}$-ingot. An added energy conservation of 50 to $100 \times 10^{3} \mathrm{kcal} / \mathrm{t}$-ingot can also be expected from resultant improvements in the process yields between molten steel and slab.

The continuous casting ratio (output of slabs/output of crude steel) of integrated steelworks in Japan, which is already as high as $40 \%$, is expected to increase further.

\section{Direct Rolling}

Consisting of direct rolling of hot ingots or slabs without reheating, direct rolling provides an attractive means of energy conservation. The net benefit of this is the saving in the reheating furnace fuel con- sumption of 300 to $500 \times 10^{3} \mathrm{kcal} / \mathrm{t}$-slab less the resultant increase in energy requirement for rolling (increased power consumption for rolling due to lower slab temperatures plus increased fuel consumption due to increased soaking temperatures if practised), estimated at around 300 to $350 \times 10^{3} \mathrm{kcal} / \mathrm{t}$-slab in total.

As with the hot charge approach, automation techniques for hot detection and conditioning of defective slabs and careful matching between the tapping and rolling schedules should be established in order to raise the direct rolling ratio.

\section{Combination and Continuous Integration of Processes}

As already discussed, combination of adjacent processes offers not only substantial energy savings but also many advantages in yields and productivities. A typical realization of this concept can be seen in an advanced facility which incorporates in a single continuous line electrolytic cleaning, batch annealing, temper rolling and product inspection with the resultant energy conservation amounting to 100 to $150 \times$ $10^{3} \mathrm{kcal} / \mathrm{t}$-coil.

There are many other areas in the strip rolling and treatment processes where combination and combination ard continuous integration will offer further energy savings.

\section{Recovery of Heat Loss}

We have already seen in Fig. 5 final forms of energy consumed. Figure 14 is a version of Fig. 5, in which the final forms of energy are illustrated on a temperature-to-temperature basis. In the figure, the $\mathrm{X}$ coordinate represents temperatures of waste heat while the $\mathrm{Y}$ coordinate represents the types of waste heat and the relative importance of each type to the total quantity of waste heat $(=100 \%)$. From this figure, the order of priority for waste heat recovery and the technical and economic feasibility of waste heat recovery can be forecast. In practical study of waste heat recovery, the following must be taken into consideration :

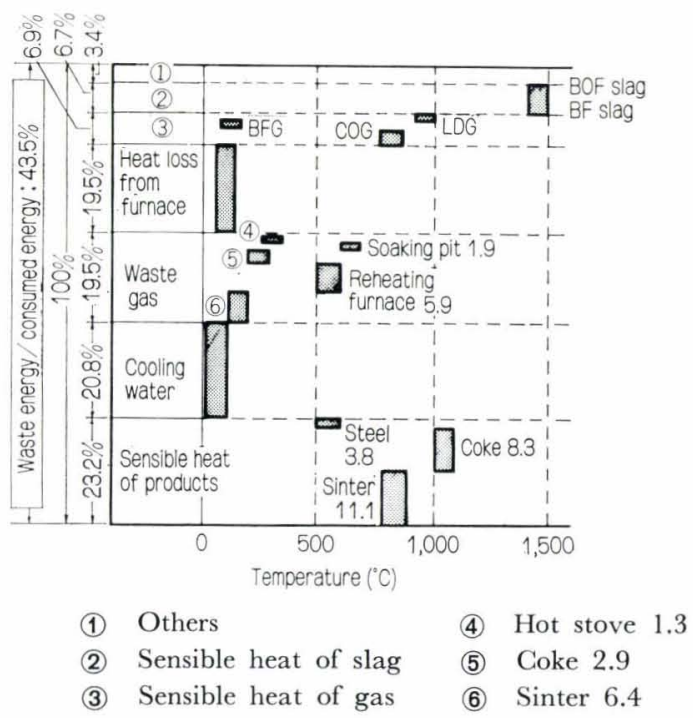

Fig. 14. Relative distribution of waste energy by form and temperature (At Nippon Steel Corp., for 1st half of fiscal 1975). 
(1) Stability of sources of waste heat (e.g., change with time);

(2) Forms in which waste heat is recovered (i.e., steam, electricity, preheated air, etc.);

(3) Destination and method of transportation of recovered energy; and

(4) Stability of recovery equipment (measures to be taken in the event of shutdown, etc).

Generally, waste heat can be recovered most readily in the form of steam. If waste heat is recovered as steam, however, prior considerations must be given to the destinations of recovered steam and to an alternative source of steam that can take over the recovery equipment when the latter is shut down. This consideration suggests that such a waste energy recovery system should desirably be so planned that recovered energy can be utilized at the source of such waste. Recovered steam, if converted into electricity, would offer easy-to-use energy, though the overall recovery efficiency would necessarily be extremely low.

\section{Recovery of Sensible Heat from Waste Gas}

As seen in Fig. 5, the combustion waste gas takes away $8.5 \%$ of the total energy input in the steelworks. Waste gas discharged from reheating furnaces and soaking pits is at high temperature and has higher values of use than others. Conventional uses of this energy have been confined, however, to preheating of combustion air. The problem is therefore how to find other uses.

Recovery of waste heat from coke ovens and hot stoves, though low in temperature, is now under study and in some steelworks sensible heat of waste gas from hot stoves is being used to preheat combustion air.

\section{Recovery of Sensible Heat of Product}

The sensible heat of relatively high temperature products, offers an attractive source of heat recovery. For example, the sensible heat of sinter is used to preheat combustion air for ignition furnaces and the sensible heat of coke has been finding applications as heat source for the production of steam for dry quenching. Also, a typical example of recovery of sensible heat from steel products can be seen in slab boilers.

Recovery of waste heat from BF and BOF slags is also on the horizon, but the general impression is that establishment of recycling techniques for these slags will assume priority.

\section{Recovery of Sensible Heat from Cooling Water}

The sensible heat of cooling water, relatively great in quantity but low in temperature, does not seem economical at the current standards of recovery techniques and energy prices. Though not yet practised in Japan, however, evaporative cooling systems are already in service in Europe and the Soviet Union for the recovery of steam from cooling water for reheating furnaces.

\section{Intensified Control of Energy Distribution and Resultant Energy Conservation}

Every steelworks has within it various sources of energy-primary energy (purchased) such as coal and fuel oil, secondary energy (by-product) such as BFG and COG and tertiary energy such as steam and internally produced electricity, to which energy recovered from waste heat is to be added. Surplus gas supply is wasted due to varying relations between production and consumption of energy (because of, for example, emergency shutdown or scheduled shutdown of equipment) and to limitations in the capacity of by-product gas holders. Because of this, such an energy distribution control system as will minimize such energy loss is essential.

In addition, further studies will also be necessary to investigate the optimum system of distribution of different types of fuel of varying calorific values to different processes that will minimize heat absorbed by waste gas; the optimum proportioning of purchased electricity and plant-generated electricity; the optimum way of emission control for $\mathrm{SO}_{x}$ and $\mathrm{NO}_{x}$.

\section{Anti-pollution Measures and Energy Conservation}

The amount of energy required for running pollution control equipment in the steel industry, though varying depending on the definition of the term, has shown a steady increase year after year. An average steelworks today consumes as much as $200 \times 10^{3} \mathrm{kcal} /$ t-steel of energy for this purpose. As emission control standards for $\mathrm{SO}_{x}$ and $\mathrm{NO}_{x}$ become severer, the figure is expected to increase further.

Figure 15 indicates a standard consumption of energy per hour for environmental protection by a steelworks with a production capacity of 6.5 million tons of crude steel per year.

Most of this consumption is electricity, about 10 to $20 \%$ of the total electricity consumption of the steelworks.

Under the situation, the steel industry is ever more eager to develop energy-saving techniques for environmental protection.

\section{Conclusion}

In the above, various problems relating to energy conservation in the steel industry are discussed from the standpoint that a steelworks itself comprises an energy system. As discussed at the beginning of this article, it can be said that the history of steelmaking technologies has been a history of selection of sources of energy, or of energy conservation technologies. In a stricter sense, however, the history of energy conservation techniques is yet in its infancy. As already noted, even what is termed "energy" is not yet defined clearly. Furthermore, in this article too, no definite characteristic or precise meaning is established as to the overall energy consumption of steelworks usually expressed in calorific value per ton of crude steel. Also for the energy model, reference is made only to the necessity for using both dynamic and static models.

Though initially stressing the concept of systems approach, therefore, this article is based in many respects on individual results that have been achieved to date. In this sense, this paper offers only a clue to stricter and more theoretical studies to be carried 


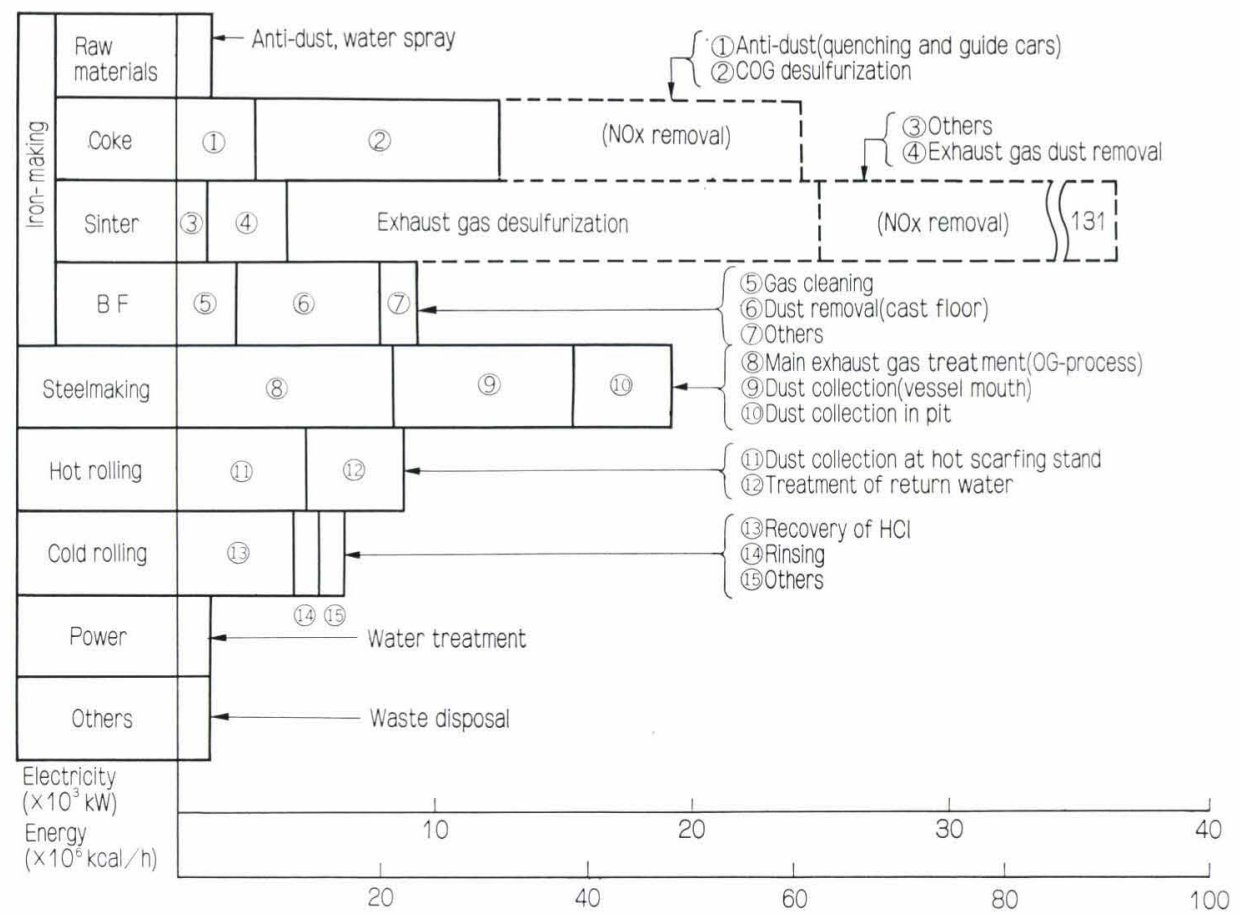

Fig. 15. Energy consumption for environmental protection (per hour).

out henceforth on various aspects of energy conservation at steelworks. Admittedly, this paper includes some parts that have not been adequately described because of the extremely wide scope of the theme and others that have been intentionally referred to despite lack of detailed study.

One of the fundamental problems together with problems of raw materials availability and environmental protection that hold a key to the future success of the Japanese steel industry, the energy issue will continue to be a subject deserving further extensive study.

\section{REFERENCES}

1) Overall Energy Statistics, ed. by Agency of Natural Resources and Energy, (1977).

2) Data presented at the 61st Meeting of the Heat Economy Technology Committee, Joint Research Society, ISIJ, (1977).

3) C. Ikeda: Tetsu-to-Hagané, 63 (1977), 1909.

4) T. Katada: "An Overall Study of Energy Conservation at Steelworks", The 39th Nishiyama Memorial Lecture, (1976), 55.

5) Data presented at the 56th Meeting of the Heat Economy Technology Committee, Joint Research Society, ISIJ, (1975), 55. 